\title{
HER2 expression as a potential marker for response to therapy targeted to the EGFR
}

\author{
DR Emlet', R Schwartz', KA Brown', AA Pollice', CA Smith' and SE Shackney*,I \\ 'Laboratory of Cancer Cell Biology and Genetics, Department of Human Oncology, Drexel University College of Medicine, Allegheny General Hospital, \\ 320 East North Avenue, Pittsburgh, PA 15212, USA; ${ }^{2}$ Department of Biological Sciences, Carnegie Mellon University, Pittsburgh, PA 152 13, USA
}

Since human epidermal growth factor receptor 2 (HER2) is known to participate with the epidermal growth factor receptor (EGFR) in mitogenic signalling, we hypothesised that HER2 overexpression might indicate responsiveness to EGFR targeted therapies. MCF7 breast cancer cells transfected with the HER2 gene were subcloned to establish a set of genetically related cell lines expressing graded levels of HER2 by immunoblot analysis. The subcloned cell lines and parental MCF7 cells were characterised by their growth characteristics, and cell by cell patterns of EGFR, HER2 and HER3 expression as well as levels of phosphorylated mitogen-activated protein kinase (MAPK) and AKT by laser scanning cytometry (LSC). Growth inhibition assays were used to characterise response to EGFR targeted therapy, and to determine the relationship between therapeutic response and levels of tyrosine kinase expression. The levels of growth inhibition of AGI478 and of the AGI478-trastuzumab combinations were correlated with levels of HER2 expression among the different cell lines. Among EGFR, HER2 and HER3, HER2 overexpression was the best single predictive marker, but combinations of two markers provided additional predictive information.

British Journal of Cancer (2006) 94, I | 44- I I53. doi: I 0.I038/sj.bjc.6603078 www.bjcancer.com

Published online 4 April 2006

(C) 2006 Cancer Research UK

Keywords: HER2; EGFR; HER3; trastuzumab; targeted therapy; breast cancer

Human epidermal growth factor receptor 2 (HER2), a member of the epidermal growth factor receptor (EGFR) family of tyrosine kinases, is overexpressed in $25-30 \%$ of human breast cancers (Slamon et al, 1987, 1989). It has been implicated in cancer progression (Yarden, 2001; Nahta and Esteva, 2003), and has been identified as a prognostic and predictive marker for breast cancer outcome (Winston et al, 2004). Breast cancers with HER2 gene amplification and/or protein overexpression have been shown to be responsive to trastuzumab (Herceptin), a humanised monoclonal antibody directed against the extracellular domain of HER2 (Baselga, 2001; Arteaga and Baselga, 2004). Trastuzumab produces high objective response rates and prolongation of overall survival as a single agent (Vogel et al, 2002) and in combination with chemotherapy (Slamon et al, 2001). Several assays, based on immunohistochemistry (IHC) or fluorescence in situ hybridisation (FISH), are FDA-approved for the clinical identification of breast cancer patients who are likely to respond to trastuzumab (Winston et al, 2004). The clinical usefulness of trastuzumab in breast cancer may be due in part to the robustness and wide availability of these standardised assays.

The EGFR is expressed in $15-35 \%$ of breast cancers, and is also associated with a poor prognosis (Thor et al, 2001; Suo et al, 2002). Agents targeted against the EGFR have been studied extensively in the laboratory, and several have undergone clinical trials,

*Correspondence: SE Shackney; E-mail: shackney@wpahs.org Revised 7 March 2006; accepted 8 March 2006; published online 4 April 2006 including Cetuximab (Erbitux), a humanised monoclonal antibody directed against the extracellular domain of the EGFR, and the small molecule tyrosine kinase inhibitors (TKIs) Gefitinib (Iressa/ ZD1839), and Erlotinib (Tarceva/OSI-774). These agents have demonstrated clinical activity in $8-20 \%$ of patients with nonsmall-cell lung cancer (NSCLC), especially in a subset of NSCLC patients whose tumours contain mutations involving the ATP binding pocket of the EGFR (Lynch et al, 2004; Paez et al, 2004). Although preclinical cell culture and xenograft studies suggest that EGFR targeted therapies hold promise for certain subtypes of breast cancer, clinical trials to date have shown responses in less than $10 \%$ of patients (Konecny et al, 2003; Arteaga and Truica, 2004; Kaklamani and O’Regan, 2004).

Tumour EGFR expression has not proven to be a useful predictive marker of clinical response to EGFR-targeted therapies (Johnson and Arteaga, 2003; Campiglio et al, 2004). There is no clear correlation between EGFR expression and response to Erlotinib, Gefitinib or Cetuximab efficacy in NSCLC or colorectal cancer (Saltz et al, 2001; Fukuoka et al, 2003; Johnson and Arteaga, 2003; Perez-Soler, 2004; Saltz et al, 2004; Noberasco et al, 2005). This may be due in part to the lack of a standardised protocol and grading system for EGFR expression in clinical samples (Noberasco et al, 2005; Younes, 2005), to technical limitations that are inherent in immunohistochemical methods (Younes, 2005), or, perhaps, to an intrinsically poor correlation between the level of EGFR expression and therapeutic response (Arteaga and Baselga, 2004).

Robust predictive markers are needed in order to identify the relatively small subsets of patients whose tumours are likely to respond to EGFR-targeted therapies (Baselga, 2002; Castro, 2002; 
Arteaga and Baselga, 2003). Candidate markers include phosphorylated EGFR (Arteaga and Baselga, 2003; DiGiovanna et al, 2005), and phosphorylated effector molecules downstream of the EGFR, such as the mitogen-activated protein kinase (MAPK) and protein kinase B (AKT) (Lynch et al, 2004; Han et al, 2005). However, there are concerns about the stability of phosphorylated proteins in primary tumour samples prior to fixation, and protocols for the collection and processing of clinical material for phosphorylated protein analysis have yet to be validated and standardised (Baselga, 2002; Lynch et al, 2004).

Human epidermal growth factor receptor 2 and the EGFR are known to heterodimerise with one another to drive mitogenic signalling pathways, and heterodimerisation has been shown to inhibit internalisation and degradation of the EGFR (Lenferink et al, 1998). Thus, receptor interactions involving HER2 may play key roles in breast cancer cells that both overexpress HER2 and express the EGFR. Epidermal growth factor receptor inhibitors are effective in blocking HER2 mediated signalling in HER2 overexpressing breast cancer cell lines that co-express the EGFR, and combinations of EGFR and HER2 targeted agents have been shown to have additive or synergistic effects on growth inhibition (Moasser et al, 2001; Moulder et al, 2001; Normanno et al, 2002; Anido et al, 2003). A recent clinical study has suggested that the adverse prognostic value of HER2 overexpression occurs only with HER2 activation or EGFR co-expression in breast cancer (DiGiovanna et al, 2005). In another recent clinical study in NSCLC, increased HER2 gene copy number was associated with sensitivity to gefitinib in EGFR-positive patients (Cappuzzo et al, 2005).

To investigate the potential role of HER2 as a predictive marker for responsiveness to EGFR targeted therapies, we developed a series of MCF7 breast cancer cell line subclones that express graded levels of HER2. Despite heterogeneity of levels of EGFR and HER3 expression, levels of MAPK and AKT phosphorylation, and overall growth rates among the different cell lines, the inhibition of tumour cell proliferation by AG1478 alone or in combination with trastuzumab was correlated with levels of expression of HER2.

\section{MATERIALS AND METHODS}

\section{Generation of HER2 transfectant cell lines}

cDNA encoding human HER2 was excised from a pLXSN retroviral expression construct (Riese et al, 1995) by digestion with Xho1, and inserted into the mammalian expression vector pcDNA 3.1 encoding geneticin resistance. Plasmids containing the correctly oriented insert were identified by restriction digest mapping followed by sequencing of the $5^{\prime}$ and $3^{\prime}$ ends of the insert. The HER2-pcDNA 3.1 construct was transfected into the breast cancer cell line MCF7 utilising a BioRad Gene Pulser Xcell. MCF7 cells were grown to $80-90 \%$ confluence and fed the day before transfection. Cells were trypsinised, centrifuged, and resuspended at a concentration of $1 \times 10^{7}$ cells ml $^{-1}$ in culture medium. A measure of $400 \mu \mathrm{l}$ of the cell suspension was mixed with $100 \mu \mathrm{g}$ of DNA construct in a $0.4 \mathrm{~cm}$ gap electroporation cuvette (BioRad, Hercules, CA, USA), and incubated at $4^{\circ} \mathrm{C}$ for $10 \mathrm{~min}$ on ice. The transfection mixture was electroporated at $220 \mathrm{~V}$ and $950 \mu \mathrm{F}$ and plated into two $100 \mathrm{~mm}$ tissue culture plates. The transfected cells were cultured overnight for recovery and then cultured in the appropriate selective media for 4-8 weeks. Resultant colonies or cell pools were subcloned by colony transfer and plating of cell pools into 24-well plates at an average ratio of 2 cells per well. Individual neomycin resistant clones were expanded and assayed for HER2 expression by immunoblot analysis. SKBR3 (an unrelated HER2 overexpressing breast cancer cell line) was used as an independent comparative reference for HER2 expression in the immunoblots.

\section{Cell culture and preparation}

JC 1939, MCF7, and SKBR3 breast cancer cell lines were maintained in RPMI 1640 containing $100 \mathrm{U} \mathrm{ml}^{-1}$ penicillin and streptomycin, $0.25 \mu \mathrm{g} \mathrm{ml}^{-1}$. amphotericin $\mathrm{B}$, and $10 \%$ fetal bovine serum (FBS). The HER2 transfected clonal cell lines were cultured in the same media supplemented with $500 \mu \mathrm{g} \mathrm{ml}^{-1}$ geneticin.

\section{Immunoblot analysis}

Cell lysate $(50 \mu \mathrm{g})$ was subject to SDS-PAGE on $4-20 \%$ tris/ glycine gels, transferred onto nitrocellulose filters, and blocked for $0.5 \mathrm{~h}$ in TTBS (100 mM Tris, $\mathrm{pH} 7.5,0.9 \% \mathrm{NaCl}, 0.1 \%$ Tween-20) with $5 \%$ nonfat dry milk. A monoclonal antibody against HER2 (clone CB11, Novacastra Laboratories, Newcastle-upon-Tyne, UK) was used at a 1:1000 dilution. The secondary antibody was goat anti-mouse horseradish peroxidase (HRP) conjugated antibody (Santa Cruz Biotechnology), and was used at a $1: 1000$ dilution. Antibody signal was visualised using the SuperSignal West Pico Chemiluminescent Substrate (Pierce) exposed to Kodak BioMax XAR film. Densitometry was performed using a Personal Densitometer SI (Molecular Dynamics), and the data were analyzed using Scion Image for Windows (Scion Corporation, Medford, MA, USA).

\section{Laser scanning cytometry (LSC) analysis}

For LSC analysis, cell lines plated into $75 \mathrm{~cm}^{2}$ flasks at $2.5 \times 10^{6}$ cells flask $^{-1}$ and harvested in log phase growth by trypsinisation were treated with cold $\left(4^{\circ} \mathrm{C}\right) 5 \mathrm{~mm}$ dithiothreitol (DTT) for $15 \mathrm{~min}$ at room temperature to reduce clumping and fixed in $0.5 \%$ paraformaldehyde and $70 \%$ methanol as described previously (Pollice et al, 1992). Aliquots of $2 \times 10^{4}$ cells from each of the cell lines were filtered through $64 \mu \mathrm{m}$ nylon mesh (Small Parts), and centrifuged at $200 \mathrm{~g}$ for $2 \mathrm{~min}$. For EGFR family member analysis, monoclonal antibodies against HER2 (clone CB11, Novacastra Laboratories), EGFR (clone EGFR.1, BD Pharmingen, San Diego, CA, USA), and HER3 (clone Ab 5, Oncogene Research Products, La Jolla, CA, USA), directly conjugated to FITC, $\mathrm{PE}$ and $\mathrm{Cy} 5$, respectively, were used at a $1: 10$ dilution in a 1-h incubation at room temperature in the dark. For the phosphorylated (P) MAPK and AKT analysis, monoclonal antibodies against P-MAPK (clone E10, Cell Signaling Technology, Beverly, MA, USA) and P-AKT (clone 4E2, Cell Signaling Technology) directly conjugated to $\mathrm{Cy} 5$ and $\mathrm{Cy} 3$, respectively, were used. Cell suspensions were washed $1 \times$ with PBS and resuspended in $100 \mu \mathrm{l}$ of $4^{\prime}, 6$-diamidino-2-phenylindole (DAPI) (Sigma) at a final concentration of $1 \mu \mathrm{g} \mathrm{ml}^{-1}$ in $\mathrm{vv}^{-1} 1: 1$ glycerol:PBS. $100 \mu \mathrm{l}$ of cell suspension was pipetted into a HybriWell chamber $\left(22 \times 22 \times 0.15 \mathrm{~mm}^{3}\right) \quad$ (Schleicher\&Schuell) affixed to precleaned glass microscope slides. Fluorescence measurements were made using a laser scanning cytometer (LSC) (CompuCyte) with the WinCyte (version 3.6) program, equipped with an air-cooled violet diode laser emitting at a wavelength of $405 \mathrm{~nm}$, an air-cooled argon laser emitting at a wavelength of $488 \mathrm{~nm}$, and an a HeNe laser emitting at a wavelength of $633 \mathrm{~nm}$. DAPI fluorescence was measured using a $463 / 39 \mathrm{~nm}$ band pass filter, FITC fluorescence was measured using a 530/30 nm band pass filter with a 555-nm dichroic long pass filter, CY3 fluorescence was measured using a 580/30-nm band pass filter with $605-\mathrm{nm}$ dichroic long pass filter and CY5 fluorescence was measured using a 650-nm long pass filter with a full mirror. A fixed scan area of $1.6 \times 10^{8} \mu \mathrm{m}^{2}$ centred on the HybriWell chamber was used with all samples. DNA was used as the contouring parameter with a threshold of 700 and 30 pixels added to threshold. For quantitation of EGFR, HER2 and HER3 in molecules per cell, the reference cell line JC 1939 was subjected to ELISAs (Oncogene Science, Carpenteria, CA, USA) with the 
appropriate antibodies. Fluorescence signal in each cell line from LSC analysis was normalised to the signal from JC 1939 to determine molecules per cell.

\section{Proliferation assays/inhibitor analysis}

The EGFR inhibitor AG1478 was purchased from Calbiochem, La Jolla, CA, USA, and was stored at $-20^{\circ} \mathrm{C}$ as a $10 \mathrm{~mm}$ stock in DMSO. Trastuzumab was a gift from Genentech. Cell stocks were grown to $80 \%$ confluence, trypsinised, and plated in triplicate into 12 -well tissue culture plates at $2 \times 10^{4}$ cells well $^{-1}$. The following day, duplicate wells (for day 0 counts) were trypsinised and each well was counted in triplicate with a haemocytometer. The remaining wells were fed every other day with regular cell culture media supplemented with appropriate inhibitor or DMSO as vehicle control. On day 6 , the remaining wells were trypsinised and counted in triplicate with a hemocytometer, and the data were graphed in Excel.

\section{Statistical analysis}

Statistical analyses were performed using SPSS version 12.0 for Windows. Human epidermal growth factor receptor 2 expression, cell growth and drug treatment data were analyzed by one-way ANOVA followed by a two-sided Dunnett's test post hoc for the determination of differences between groups. Pearson correlation coefficients of linear regression were calculated for $-\log$ of surviving cell fraction $v s$ relative HER2 expression.

The combination index (CI) for drug effect in each cell line was calculated from the surviving cell fractions of cells treated with each drug alone, $\mathrm{SF}_{\mathrm{A}}$ and $\mathrm{SF}_{\mathrm{B}}$, and the surviving cell fractions of cells treated with the drug combination, $\mathrm{SF}_{\mathrm{AB}}$, where $\mathrm{CI}=\mathrm{SF}_{\mathrm{AB}} /$ $\left(\mathrm{SF}_{\mathrm{A}} \times \mathrm{SF}_{\mathrm{B}}\right)$. Triplicate analyses were subjected to two-sided statistical tests (1-group, two-tailed test with degrees of freedom $=2$ ) to determine if the mean CI value for each cell line was significantly different from a CI of 1.0 at the $P<0.05$ level. Synergy was defined by a CI value that was significantly $>1.0$, and antagonism was defined by a CI value significantly greater than 1.0. Effects were considered additive if the CI was not significantly different from 1.0.

\section{Prediction of treatment outcomes}

Least-squares linear regression analysis was applied to correlate protein expression levels with efficacy ratios of trastuzumab and AG1478 on the parental MCF7 and HER2 expressing subclones. Mean expression of EGFR, HER2 and HER3 were derived from cell-based measurements of molecules per cell by LSC. Drug efficacy ratios were derived for each treatment by taking one minus the ratio of cells counted following treatment to cells counted without treatment. A linear regression model was defined to relate efficacy ratio $(k)$ to mean expression levels of EGFR, HER2 and HER3 using the formula

$$
k \approx a_{1}[\mathrm{EGFR}]+a_{2}[\mathrm{HER} 2]+a_{3}[\mathrm{HER} 2]
$$

Constants $a_{1}, a_{2}$ and $a_{3}$ were derived to provide a least-squares fit between observed and predicted efficacy ratios across the cell lines examined. Least-squares regression was further attempted for each of the three assayed genes in isolation, using models of the form

$$
\begin{aligned}
& k \approx \tilde{a}_{1}[\mathrm{EGFR}] \\
& k \approx \tilde{a}_{2}[\mathrm{HER} 2] \\
& k \approx \tilde{a}_{3}[\mathrm{HER} 3]
\end{aligned}
$$

where each of the $\tilde{a}_{1}, \tilde{a}_{2}$ and $\tilde{a}_{3}$ constants was derived to provide a least-squares best-fit between the observed efficacy ratios and those predicted from the single gene in isolation. Each of these linear regression analyses was tested by leave-one-out cross validation. For each cell line, parameters were fit without using the data provided by that cell line and the efficacy ratio for the missing cell line was predicted from the derived parameters. The root mean square errors of the predictions were assessed for all regression analyses with and without the cross-validation.

\section{RESULTS}

Generation of MCF7 subclones that overexpress HER2 at graded levels, and analysis of growth characteristics

The MCF7 breast cancer cell line was transfected with a pcDNA 3.1 construct encoding human HER2 that was derived from a retroviral construct (Riese et al, 1995), and HER2 expressing clones were identified by immunoblot analysis (Figure 1A). Clones were isolated that overexpress low (NH33, NH42 and NH77), intermediate (NH13, NH29 and NH47), or high (NH131 and NH27) levels of HER2 by comparison with the parental MCF7 line. The cell lines with the highest level of HER2 expression exhibit levels that approach that found in the endogenously high HER2 overexpressing SKBR3 cell line. Quantitative densitometry measurements on HER2 immunoblots from multiple passages of these clones are shown in Figure 1B. The growth rates and levels of HER2 expression of the subclones were monitored at each passage to ensure stability.

The relative growth rates of the transfected cell lines are shown in Figure 1C. The HER2 transfected clones all grow more slowly than the reference parental MCF7 line. This is consistent with previous studies that have demonstrated a decrease in the growth rate of MCF7 cells with HER2 transfection and overexpression (Giani et al, 1998; Huang et al, 2002). The low HER2 overexpressing cell lines show a $45 \%$ reduction in growth rate from the parental MCF7, and the intermediate HER2 expressing clones exhibit an $85 \%$ reduction in growth rate $(P<0.05)$. The subclones in the high HER2 overexpressing group exhibit higher growth rates than the subclones with intermediate levels of HER2 expression. These findings do not support a monotonic relationship between mean HER2 expression level and growth rate.

\section{Cell by cell correlation of HER2, EGFR and HER3 expression levels in the HER2 transfectants}

Parental MCF7 cells and HER2 transfected MCF7 subclones were grown to subconfluence, and fed with normal culture media $24 \mathrm{~h}$ prior to trypsinisation and cell fixation. The fixed cells were stained with fluorochrome conjugated antibodies against the EGFR, HER2 and HER3 and analyzed by LSC. The results, expressed in molecules per cell and correlated cell by cell, are shown in Figure 2. The HER2 level for each cell is plotted on the abscissa, and the HER3 level for each cell is plotted on the ordinate. The EGFR level for each cell line is shown using a series of colour-coded symbols as indicated in the figure legend. In all cell lines, there is a correlation between levels of HER2/cell and levels HER3/cell in the same cells, as well as between HER2/cell and EGFR/cell, and EGFR/cell and HER3/cell (see Supplementary Table 1S).

It is apparent that despite the overall correlations among levels of HER2, EGFR and HER3 in the same cells, there are substantial differences among the different subclones with respect to the ranges of levels of expression of these cell constituents. Human epidermal growth factor receptor 2 levels are lowest in the parental MCF7 cell line and highest in NH27 cells, but NH27 cells have neither high levels of HER3 nor the highest levels of EGFR per cell. In most of the MCF7 subclones that contain high EGFR overexpressing cells, the cells with EGFR levels exceeding 80000 molecules per cell exhibit only moderately elevated levels of HER2 (mostly in the range of 200000-600000 molecules per 
A
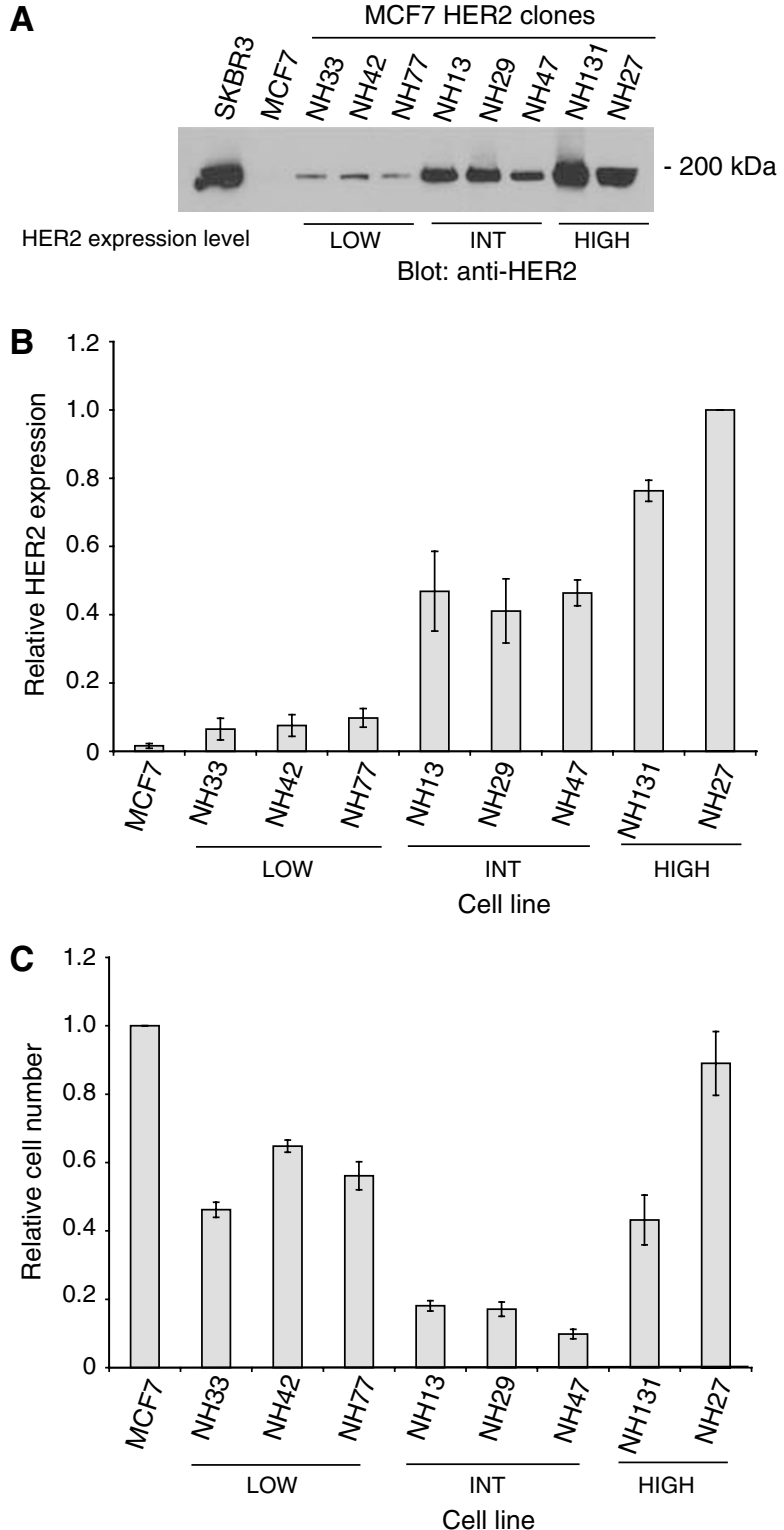

Figure I Stable HER2 expression levels and growth characteristics of HER2 transfected MCF7 subclones. (A) HER2 expression by immunoblot analysis in HER2 cDNA vector transfected MCF7 cell lines overexpressing low (LOW), intermediate (INT) and high (HIGH) levels of HER2 compared to parental MCF7 and SKBR3 breast cancer cell lines. The position of the molecular weight marker is shown on the right. (B) Exposures from three separate immunoblots of the MCF7 subclones were subjected to densitometry, and density values were normalised to the HER2 value from the NH27 cell line. The means of the HER2 signals from the LOW, INT and HIGH groups are statistically significantly different from one another and from the MCF7 signal $(P<0.01$ in each comparison), except for the MCF7 vs the LOW HER2 expressing subclones $(P=0.462)$. (C) Total cell number relative to control MCF7 after 6 days of growth for the HER2 transfected MCF7 subclones. Results of three independent experiments were normalised to the mean of parental MCF7 cells. Bars, + s.e.

cell). However, in NH27 cells, among the few that exhibit EGFR levels in excess of 80000 molecules per cell, most also have HER2 levels that exceed 600000 molecules per cell. Thus, across subclones, there is a relationship between levels of EGFR expression and HER3 expression per cell that is worth pursuing (see below), but there does not appear to be a strict quantitative relationship between increased EGFR levels and/or HER3 levels on the one hand and increasing HER2 levels on the other.

\section{Cell by cell levels of P-MAPK and P-AKT}

Parental MCF7 cells and HER2 transfected MCF7 subclones were prepared for LSC, and stained with antibodies against the phosphorylated forms of MAPK and AKT. Correlated cellular levels of P-MAPK and P-AKT were determined by LSC (Figure 3). Quantitative cellular levels of each phospho-protein are expressed in arbitrary units, where mean cellular levels obtained in concomitantly run aliquots of stored reference cells are assigned values of 10000 arbitrary units per cell. Mean levels of P-AKT range from $\sim 43000$ units per cell in NH131 cells to $\sim 87000$ units per cell in NH27 cells. Across cell lines, there is no strong correlation between mean P-AKT level per cell and HER2 level $(r=0.078, P=0.868$; see Supplementary Figure $1 S)$.

There was considerable variation in levels of P-MAPK per cell, both within and among the different cell lines (Figure 3). Across cell lines, mean levels of P-MAPK per cell varied from $\sim 28000$ units per cell in NH27 cells to $\sim 131000$ units per cell in NH47 cells. There was no correlation between mean P-MAPK level per cell and HER2 level across cell lines $(r=-0.067, P=0.886$; see Supplementary Figure 1S).

Within individual cell lines, the simultaneous measurement of P-MAPK and P-AKT in each cell by LSC reveals a strong correlation between the cellular levels of these two phosphoproteins (Figure 3). However, the slopes of the regression vary from cell line to cell line.

\section{Effects of AG1478 and trastuzumab on cell proliferation}

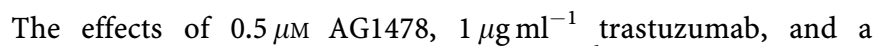
combination of $0.5 \mu \mathrm{M} \mathrm{AG1478}$ and $1 \mu \mathrm{g} \mathrm{ml}^{-1}$ trastuzumab on cell proliferation are shown in Figure 4A. These drug concentrations were estimated to fall within a clinically achievable range (Hidalgo et al, 2001; Pegram et al, 2004), and showed activity in preliminary dose response studies (see Supplementary Figure 2S). In transfected MCF7 cell subclones with modest increases in HER2 overexpression (NH33, NH42 and NH77), the effects of trastuzumab on cell proliferation (white bars, Figure 4A) are not significantly different from its effects on parental MCF7 cells. Trastuzumab decreases cell proliferation in the intermediate HER2 overexpressing group by an average of $17 \%$ in comparison with parental MCF7 cells $(P=0.005)$. In the high HER2 expressing group, trastuzumab produced an average decrease in cell proliferation that is $24 \%$ greater than in parental MCF7 cells $(P=0.004)$, but the difference in the effects of trastuzumab on intermediate and high HER2 overexpressing MCF7 subclones is not statistically significant $(P=0.244)$.

AG1478 treatment does not substantially inhibit the growth of parental MCF7 or the low HER2 overexpressing subclones (black bars, Figure 4A). Compared to parental MCF7, AG1478 has a 25 and $36 \%$ greater mean inhibition of proliferation on the intermediate $(P=0.05)$ and high $(P=0.007)$ HER2 expressing clones, respectively. However, the difference in response between the intermediate and high HER2 expressing clones is not statistically significant $(P=0.077)$.

Combined treatment of these cell lines with both AG1478 and trastuzumab (grey bars, Figure $4 \mathrm{~A}$ ) produces a significantly greater inhibition of proliferation than that of either agent alone only in cell lines with intermediate and high levels of overexpression of HER2. The drug combination produces greater inhibition of cell proliferation in the intermediate and high HER2 expressing clones in comparison with AG1478, the best single agent for these cell lines $(P<0.05)$.

When all of the cell lines in the panel are considered together, there are strong correlations between log growth inhibition by 

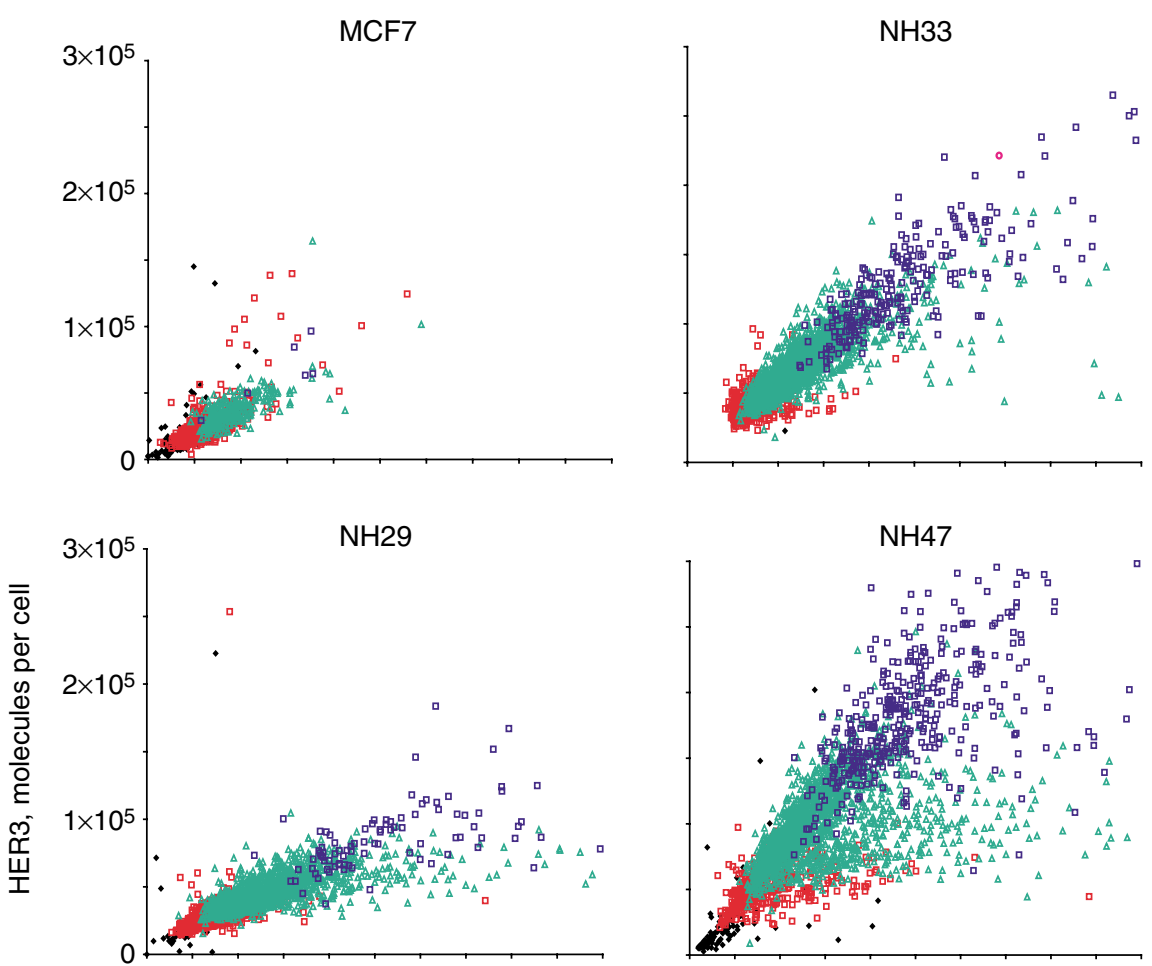

$\mathrm{NH} 131$

$\mathrm{NH} 27$
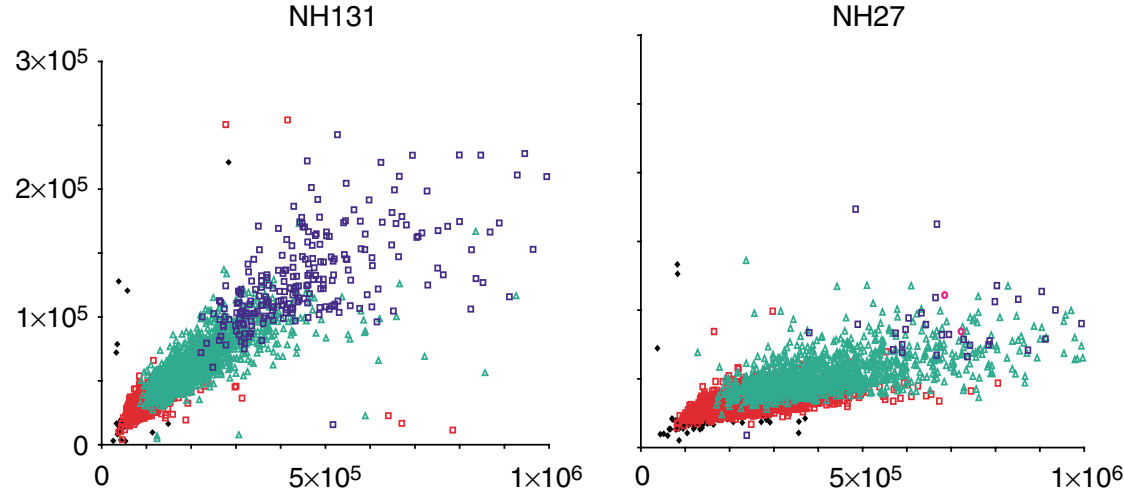

HER2, molecules per cell

Figure 2 Laser scanning cytometry analysis of EGFR, HER2 and HER3 expression in parental MCF7 and MCF7 HER2 transfected subclones. Parental MCF7 and HER2 transfected subclones were trypsinised, stained with fluorochrome-conjugated antibodies directed against the EGFR, HER2 and HER3, and subjected to multiparameter LSC analysis. Correlated cell-by-cell fluorescence measurements are shown with HER2 expression plotted on the abscissa, HER3 expression plotted on the ordinate, and EGFR expression plotted as object/colour coded: EGFR $<20000$ molecules cell $^{-1}$ (black diamonds), EGFR 20000 to $<40000$ molecules per cell (open red squares), EGFR 40000 to $<80000$ molecules per cell (open green triangles), EGFR $>80000$ molecules per cell (open blue squares). All receptor level values are expressed as receptor numbers per cell, based on known mean values (determined independently by ELISA) in a concomitantly run reference cell line, and corrected for autofluorescence, cell aggregates and fluorescence channel crosstalk.

each drug individually or in combination and mean levels of HER2 expression in the cell lines (Figure 4B). There is a strong correlation between the degree of cell growth inhibition by trastuzumab and HER2 expression level $(r=0.945, P=0.0001$; Figure 4B, left panel), between AG1478 and HER2 expression level $(r=0.934 ; P=0.0002$; Figure $4 \mathrm{~B}$, middle panel), and between the degree of cell growth inhibition by combined treatment (AG1478 plus trastuzumab) and HER2 expression level $(r=0.909$, $P=0.0006$; Figure 4B, right panel).

To further characterise the interaction between the effects of AG1478 and trastuzumab, the CI was calculated for each cell line (Table 1). Overall, the CIs suggest that the combined drug effect is additive, except in the NH27 cell line, where synergy was clearly demonstrated. However, since the overall effects of these agents are small in the low HER2 expressing lines, the CI results may be difficult to interpret in these cell lines.

\section{Prediction of efficacy of AG1478, trastuzumab and the combination of AG1478 and trastuzumab from multiple receptor expression data}

We applied least-squares regression to find a best-fit linear model of drug efficacy as a function of mean EGFR, HER2 and HER3 expression levels derived from LSC measurements of parental MCF7 and HER2 transfected subclones (Table 2). Using the three receptor levels individually as predictors of trastuzumab efficacy with leave-one-out cross-validation, the root mean square prediction errors are 0.099 for HER2 alone, 0.123 for EGFR alone, and 


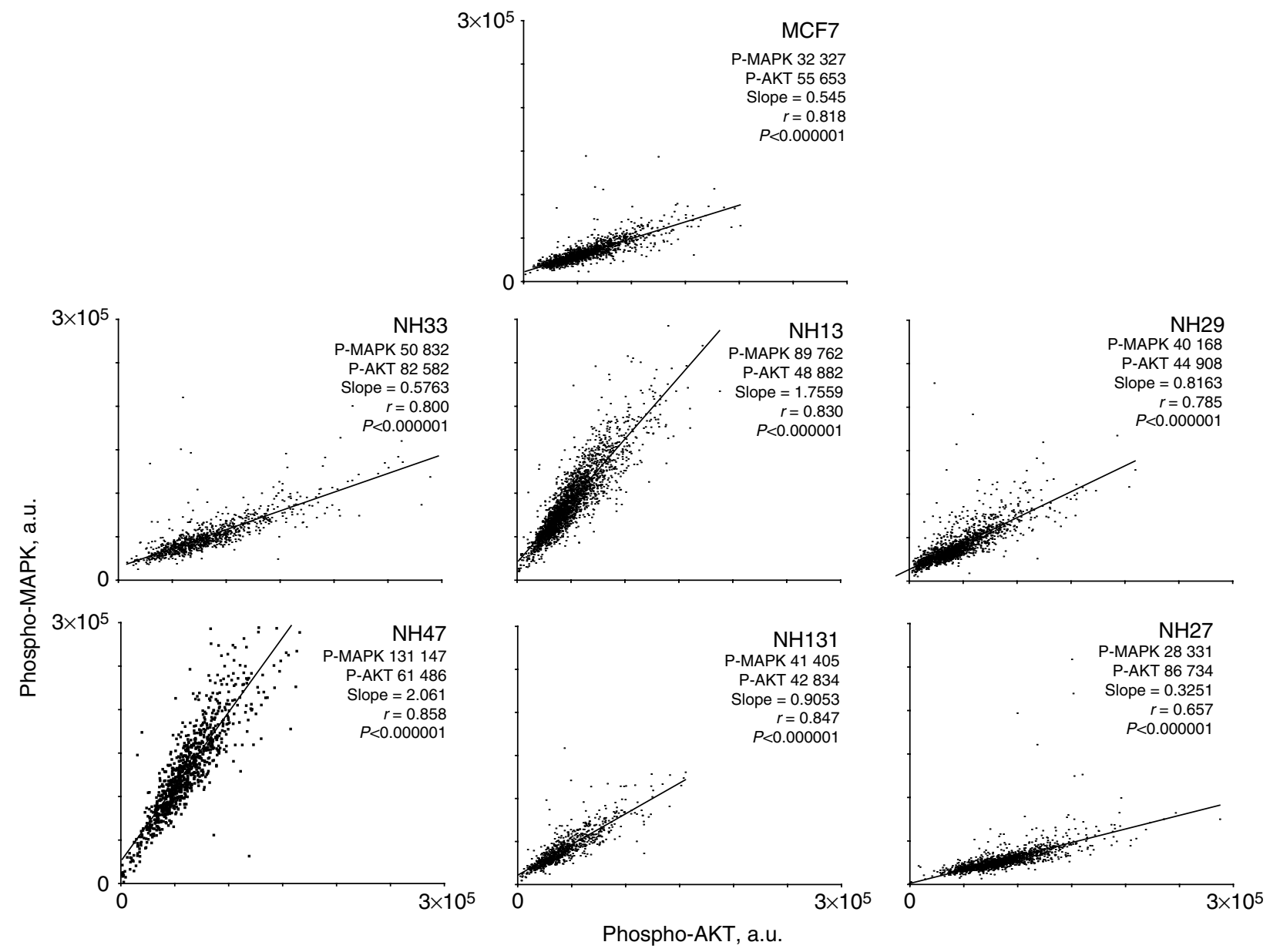

Figure 3 Laser scanning cytometry analysis of P-MAPK and P-AKT levels on a cell-by-cell basis in control and HER2 transfected MCF7 subclones. For each cell, P-MAPK level per cell is plotted on the ordinate and P-AKT level in the same cell is plotted on the abscissa. Values are corrected for autofluorescence, cell aggregates and cross talk. The mean fluorescence values for P-MAPK and P-AKT, the slope, and correlation coefficient ( $r$ ) for each cell line are shown.

0.159 for HER3 alone. Thus, HER2 is the best individual marker for the prediction of trastuzumab efficacy in these cell lines. With regard to predicting for AG1478 effect, root mean square errors are 0.192 for HER2 alone, 0.233 for EGFR alone, and 0.286 for HER3 alone, suggesting that HER2 expression level is also the best single predictor of AG1478 efficacy in these cell lines. Human epidermal growth factor receptor 2 is also the best individual predictor for combined drug efficacy.

Overall, the smallest root mean square error for prediction of trastuzumab efficacy (0.089) was achieved using a combination of HER2 and HER3 expression levels. Interestingly, the overall smallest root mean square error for prediction of AG1478 efficacy $(0.180)$ is achieved using a combination of EGFR and HER3 expression levels. Predictions using all three receptor expression levels together result in errors that were not as low as those derived from the best individual or two-receptor predictions, suggesting that the data set may be too small to draw robust inferences from the three-protein model.

\section{DISCUSSION}

It is generally agreed that there is a need for better clinical biomarkers for response to EGFR targeted therapy (Baselga, 2002; Castro, 2002; Arteaga and Baselga, 2003). Overall clinical response rates to EGFR targeted therapy in many of the common human solid tumours are generally low, often in the range of $5-20 \%$ (Castro, 2002; Fukuoka et al, 2003; Kris et al, 2003). Many patients whose tumours express EGFR fail to respond to EGFR targeted therapy, and conversely, patients who respond may have tumours that do not exhibit EGFR expression (Noberasco et al, 2005; Younes, 2005). Preclinical studies in tissue culture and in xenografts using cancer cell lines with known EGFR expression have shown that EGFR overexpression itself might not be a useful predictive marker for response to EGFR targeted therapy (Sirotnak et al, 2000; Ciardiello et al, 2000, 2001; Moasser et al, 2001; Wakeling et al, 2002; Campiglio et al, 2004). In this study, we show that growth inhibition in response to AG1478, a targeted inhibitor of the EGFR, and AG1478 in combination with the HER2 targeted antibody trastuzumab, is correlated with increased HER2 expression levels. The largest effects of these therapies are seen in the cell lines expressing the highest levels of HER2.

Human epidermal growth factor receptor 2 is known to heterodimerise preferentially with the EGFR (Graus-Porta et al, 1997), potentiate mitogenic signalling by increasing ligand affinities of the EGFR, and protect the EGFR from degradation (Tzahar et al, 1996; Lenferink et al, 1998). This could provide a mechanistic explanation for our findings. In support of this premise, EGFR and HER2 co-expression has been linked to a more aggressive clinical phenotype and to poor prognosis in breast cancer (Thor et al, 2001; Suo et al, 2002). Preclinical studies in breast cancer cell lines that overexpress HER2 show that combined 


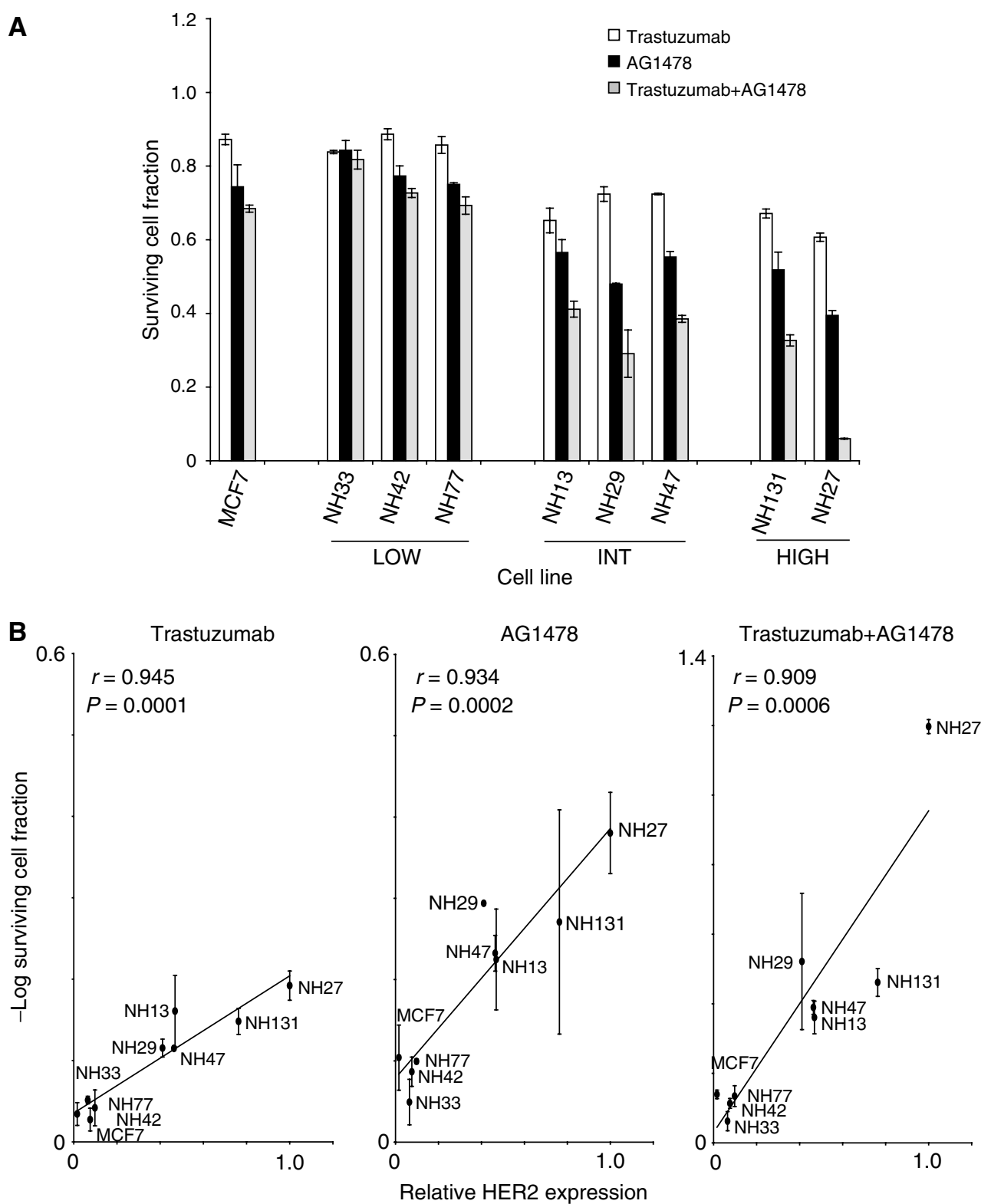

Figure 4 Effects of AGI478, trastuzumab, and a combination of AGI478 and trastuzumab on the growth of control cell lines and HER2 transfected subclones, and correlation of HER2 expression with drug efficacy. (A) Parental MCF7 control cell lines and the HER2 transfected MCF7 subclones were

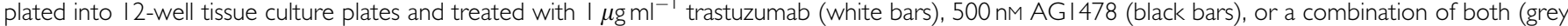
bars) for 5 days. On day 6, the cells were trypsinised, counted and the cell number from drug treated samples were normalised with respect to control cells treated with vehicle only (DMSO and human $\operatorname{lgG}$ ). (B) Mean HER2 expression level in the cell lines, normalised with respect to the HER2 content of the $\mathrm{NH} 27$ cell line, was correlated to - log of surviving cell fractions from individual drug treatments (Trastuzumab, and AGI478) and combined drug treatments (Trastuzumab + AG |478). - - log of surviving cell fraction is plotted on the ordinate, and mean HER2 expression is plotted on the abscissa. The correlation coefficient $(r)$ and $P$-value for each correlation are shown. The results are from at least three independent experiments. Bars $= \pm 95 \% \mathrm{Cl}$.

EGFR and HER2 inhibition may be more effective than treatment with single agents, regardless of EGFR expression level (Moasser et al, 2001; Moulder et al, 2001; Normanno et al, 2002; Anido et al, 2003).

Our panel of HER2-transfected subclones was intended to provide the opportunity to study the effects of targeted therapeutic agents in a family of cell lines that have few overall genotypic differences, and that express graded levels of HER2 protein. Nonetheless, there are differences among these subclones in quantitative levels of intracellular co-expression of key proteins, including HER2, EGFR and HER3 (Figure 2), and relative levels of co-expression of P-ERK and P-AKT per cell, which also vary from cell line to cell line (Figure 3). Thus, we demonstrate a direct relationship between the degree of efficacy of anti-EGFR regimens and the levels of HER2 expression in breast cancer cell lines (Figure 4A and $\mathrm{B}$ ). This supports the case for investigating the potential clinical role of HER2 overexpression as a predictive marker for response to anti-EGFR therapy in human cancers.

Other cell constituents might also predict response to anti-EGFR therapy, and some might provide independent predictive information. The data on EGFR, HER2 and HER 3 expression levels by LSC support this possibility. We have noted that high cellular levels of EGF receptor are often accompanied by high levels of HER3 in the same cells (Figure 2). The linear regression analysis shows that although increased expression of HER2 is the best single predictor for responsiveness to AG1478 or the AG1478-trastuzumab 
Table I Mean survival fractions and combination indices for trastuzumab treatment, AGI478 treatment, and AGI478+trastuzumab combination treatments

\begin{tabular}{|c|c|c|c|c|c|c|}
\hline & $\begin{array}{l}\text { Mean surviving } \\
\text { fraction with } \\
\text { AGI478 }\end{array}$ & $\begin{array}{l}\text { Mean surviving } \\
\text { fraction with } \\
\text { trastuzumab }\end{array}$ & $\begin{array}{c}\text { Mean expected } \\
\text { survival fraction for } \\
\text { additivity }\end{array}$ & $\begin{array}{l}\text { Mean observed survival } \\
\text { fraction with the } \\
\text { AG I 478+trastuzumab } \\
\text { combination }\end{array}$ & $\begin{array}{c}\text { Mean } \\
\text { combination } \\
\text { index }\end{array}$ & $\begin{array}{c}\text { P-value } \\
\text { (combination } \\
\text { index) }\end{array}$ \\
\hline $\mathrm{NH} 33$ & $0.893 \pm 0.028$ & $0.888 \pm 0.005$ & $0.793 \pm 0.028$ & $0.866 \pm 0.016$ & $1.093 \pm 0.018$ & 0.034 \\
\hline $\mathrm{NH} 42$ & $0.866 \pm 0.050$ & $0.939 \pm 0.017$ & $0.813 \pm 0.051$ & $0.770 \pm 0.008$ & $0.955 \pm 0.065$ & 0.561 \\
\hline $\mathrm{NH77}$ & $0.784 \pm 0.012$ & $0.929 \pm 0.022$ & $0.728 \pm 0.019$ & $0.734 \pm 0.014$ & $0.985 \pm 0.030$ & $0.67 \mid$ \\
\hline $\mathrm{NH} 47$ & $0.586 \pm 0.016$ & $0.767 \pm 0.002$ & $0.450 \pm 0.014$ & $0.408 \pm 0.010$ & $0.909 \pm 0.040$ & 0.149 \\
\hline NHI3I & $0.549 \pm 0.082$ & $0.711 \pm 0.008$ & $0.391 \pm 0.060$ & $0.346 \pm 0.009$ & $0.932 \pm 0.154$ & 0.701 \\
\hline $\mathrm{NH} 27$ & $0.418 \pm 0.025$ & $0.630 \pm 0.004$ & $0.264 \pm 0.017$ & $0.064 \pm 0.001$ & $0.243 \pm 0.014$ & 0.0003 \\
\hline
\end{tabular}

Mean survival fraction and combination index $(\mathrm{Cl})$ values were obtained from triplicate studies. The $\mathrm{P}$-values for each cell line indicate the level of statistical significance of the $\mathrm{Cl}$ compared with a $\mathrm{Cl}$ value of I.0. Mean $\mathrm{Cl}$ values significantly greater than $1.0(P<0.05)$ indicate antagonism, and values significantly less than I.0 $(P<0.05)$ indicate synergy. Numbers in parentheses $=$ standard error (s.e.). $\mathrm{Cl}=$ combination index.

Table 2 Comparison of root mean square errors of predicted AGI478 and trastuzumab treatment outcomes from receptor expression levels

\begin{tabular}{lccccccr}
\hline & HER2 & EGFR & HER3 & EGFR+HER2 & EGFR+HER3 & HER2+HER3 & All \\
\hline Trastuzumab & 0.099 & 0.123 & 0.159 & 0.159 & 0.133 & 0.089 & 0.146 \\
AG|478 & 0.192 & 0.233 & 0.286 & 0.344 & 0.180 & 0.286 & 0.284 \\
Combination & 0.303 & 0.370 & 0.442 & 0.509 & 0.255 & 0.442 & 0.402
\end{tabular}

Least-squares linear regression analysis was applied to receptor expression data from LSC analysis and inhibitor proliferation assay results to determine the correlation between receptor expression levels and drug treatment outcomes as described in the Materials and Methods. Predictions were made from individual receptor expression, two receptor combinations, and all three receptors together on each of the drug combinations tested. Shown is the root mean square errors derived from each drug-receptor combination.

combination (as well as for trastuzumab alone), the best combination of predictors for the efficacy of AG1478 or combined AG1478-trastuzumab is increased expression of the EGFR and HER3 (Table 2).

Of course, one cannot assume that results obtained on cell lines in vitro can be translated directly into the clinic. Additional support from experimental studies in vivo would be highly desirable. Such studies would require the development and validation of a suitable panel of tumour lines that stably overexpress graded levels of HER2 in vivo.

Several published clinical studies suggest that our findings in breast cancer cell lines might be of some relevance in the clinical setting. In a recent study of breast cancer patients, 35\% of 306 HER2-overexpressing tumours were found to express EGFR Conversely, $87 \%$ of EGFR-overexpressing tumours were found to overexpress HER2 as well (DiGiovanna et al, 2005). In a recent paper involving NSCLC patients, clinical responses to gefitinib (an anti-EGF receptor agent) were shown to be correlated with HER2 overexpression/amplification in EGF receptor-positive patients (Cappuzzo et al, 2005). It would seem reasonable to investigate the possibility of a relationship between HER2 status and response to anti-EGFR therapy in patients with breast cancer as well, based on our findings in breast cancer cell lines that responses to

\section{REFERENCES}

Anido J, Matar P, Albanell J, Guzman M, Rojo F, Arribas J, Averbuch S, Baselga J (2003) ZD1839, a specific epidermal growth factor receptor (EGFR) tyrosine kinase inhibitor, induces the formation of inactive EGFR/HER2 and EGFR/HER3 heterodimers and prevents heregulin signaling in HER2-overexpressing breast cancer cells. Clin Cancer Res 9: $1274-1283$ trastuzumab and AG1478 alone or in combination are correlated with high levels of HER2 expression.

In summary, we show that in human breast cancer cell lines increased levels of HER2 expression alone are associated with increased effectiveness of anti-EGFR therapy, alone or in combination with anti-HER2 therapy, and that the combination of EGFR and HER3 overexpression may be an even better predictor of response. This would suggest the possibility that HER2 overexpression alone and/or the combination of EGFR and HER3 expression levels might be useful clinical markers for response to EGFR and combined EGFR-HER2 targeted therapy in patients with breast cancer.

\section{ACKNOWLEDGEMENTS}

This work was supported in part by the Pennsylvania Department of Health Grant ME-01-334 and in part by Beckman Coulter Agreement \#41331809.

Supplementary Information accompanies the paper on British Journal of Cancer website (http://www.nature.com/bjc)
Arteaga C, Baselga J (2003) Clinical trial design and end points for epidermal growth factor receptor-targeted therapies: implications for drug development and practice. Clin Cancer Res 9: 1579-1589

Arteaga C, Truica C (2004) Challenges in the development of antiepidermal growth factor receptor therapies in breast cancer. Semin Oncol 31: $3-8$ 
Arteaga CL, Baselga J (2004) Tyrosine kinase inhibitors: why does the current process of clinical development not apply to them? Cancer Cell 5: $525-531$

Baselga J (2001) Clinical trials of Herceptin(trastuzumab). Eur J Cancer 37: S18-S24

Baselga J (2002) Targeting the epidermal growth factor receptor with tyrosine kinase inhibitors: small molecules, big hopes. J Clin Oncol 20: $2217-2219$

Campiglio M, Locatelli A, Olgiati C, Normanno N, Somenzi G, Vigano L, Fumagalli M, Menard S, Gianni L (2004) Inhibition of proliferation and induction of apoptosis in breast cancer cells by the epidermal growth factor receptor (EGFR) tyrosine kinase inhibitor ZD1839 ('Iressa') is independent of EGFR expression level. J Cell Physiol 198: 259-268

Cappuzzo F, Varella-Garcia M, Shigematsu H, Domenichini I, Bartolini S, Ceresoli GL, Rossi E, Ludovini V, Gregorc V, Toschi L, Franklin WA, Crino L, Gazdar AF, Bunn Jr PA, Hirsch FR (2005) Increased HER2 gene copy number is associated with response to gefitinib therapy in epidermal growth factor receptor-positive non-small-cell lung cancer patients. J Clin Oncol 23: 5007-5018

Castro M (2002) The simpleton's error in drug development. J Clin Oncol 20: $4606-4607$

Ciardiello F, Caputo R, Bianco R, Damiano V, Fontanini G, Cuccato S, De Placido S, Bianco A, G T (2001) Inhibition of growth factor production and angiogenesis in human cancer cells by ZD1839 (Iressa), a selective epidermal growth factor receptor tyrosine kinase inhibitor. Clin Cancer Res 7: 1459-1465

Ciardiello F, Caputo R, Bianco R, Damiano V, Pomatico G, De Placido S, Bianco A, Tortora G (2000) Antitumor effect and potentiation of cytotoxic drugs activity in human cancer cells by ZD-1839 (Iressa), an epidermal growth factor receptor-selective tyrosine kinase inhibitor. Clin Cancer Res 6: 2053-2063

DiGiovanna MP, Stern DF, Edgerton SM, Whalen SG, Moore II D, Thor AD (2005) Relationship of epidermal growth factor receptor expression to ErbB-2 signaling activity and prognosis in breast cancer patients. J Clin Oncol 23: $1152-1160$

Fukuoka M, Yano S, Giaccone G, Tamura T, Nakagawa K, Douillard J, Nishiwaki Y, Vansteenkiste J, Kudoh S, Rischin D, Eek R, Horai T, Noda K, Takata I, Smit E, Averbuch S, Macleod A, Feyereislova A, Dong R, Baselga J (2003) Multi-institutional randomized phase II trial of gefitinib for previously treated patients with advanced non-smallcell lung cancer (The IDEAL 1 Trial) [corrected]. J Clin Oncol 21: $2237-2246$

Giani C, Casalini P, Pupa S, De Vecchi R, Ardini E, Colnaghi M, Giordano A, Menard S (1998) Increased expression of c-erbB-2 in hormonedependent breast cancer cells inhibits cell growth and induces differentiation. Oncogene 17: 425-432

Graus-Porta D, Beerli R, Daly J, Hynes N (1997) ErbB-2, the preferred heterodimerization partner of all ErbB receptors, is a mediator of lateral signaling. EMBO J 16: $1647-1655$

Han S, Hwang P, Chung D, Kim D, Im S, Kim Y, Kim T, Heo D, Bang Y, Kim N (2005) Epidermal growth factor receptor (EGFR) downstream molecules as response predictive markers for gefitinib (Iressa, ZD1839) in chemotherapy-resistant non-small cell lung cancer. Int J Cancer 113: $109-115$

Hidalgo M, Siu L, Nemunaitis J, Rizzo J, Hammond L, Takimoto C, Eckhardt S, Tolcher A, Britten C, Denis L, Ferrante K, Von Hoff D, Silberman S, Rowinsky E (2001) Phase I and pharmacologic study of OSI-774, an epidermal growth factor receptor tyrosine kinase inhibitor, in patients with advanced solid malignancies. J Clin Oncol 19: 3267-3279

Huang G, Hobbs S, Walton M, Epstein R (2002) Dominant negative knockout of p53 abolishes ErbB2-dependent apoptosis and permits growth acceleration in human breast cancer cells. $\mathrm{Br} J$ Cancer 86: $1104-1109$

Johnson D, Arteaga C (2003) Gefitinib in recurrent non-small-cell lung cancer: an IDEAL trial? J Clin Oncol 21: 2227-2229

Kaklamani V, O'Regan R (2004) New targeted therapies in breast cancer. Semin Oncol 31: 20-25

Konecny G, Wilson C, Slamon D (2003) Is there a role for epidermal growth factor receptor inhibitors in breast cancer prevention? J Natl Cancer Inst 95: $1813-1815$

Kris MG, Natale RB, Herbst RS, Lynch TJ, Prager D, Belani CP, Schiller JH, Kelly K, Spiridonidis H, Sandler A, Albain KS, Cella D, Wolf MK, Averbuch SD, Ochs JJ, Kay AC (2003) Efficacy of gefitinib, an inhibitor of the epidermal growth factor receptor tyrosine kinase, in symptomatic patients with non-small cell lung cancer. J Am Med Assoc 290: 2149-2158
Lenferink A, Pinkas-Kramarski R, van de Poll M, van Vugt M, Klapper L, Tzahar E, Waterman H, Sela M, van Zoelen E, Yarden Y (1998) Differential endocytic routing of homo- and hetero-dimeric ErbB tyrosine kinases confers signaling superiority to receptor heterodimers. EMBO 17: 3385-3397

Lynch T, Adjei A, Bunn PJ, DuBois R, Gandara D, Giaccone G, Govindan R, Herbst R, Johnson B, Khuri F, Perez-Soler R, Rosell R, Rowinsky E, Sandler A, Scagliotti G, Schiller J, Shapiro G, Socinski M, Hart CS (2004) Novel agents in the treatment of lung cancer: conference summary statement. Clin Cancer Res 10: 4199s-4204s

Moasser M, Basso A, Averbuch S, Rosen N (2001) The tyrosine kinase inhibitor ZD1839 ('Iressa') inhibits HER2-driven signaling and suppresses the growth of HER2-overexpressing tumor cells. Cancer Res 61 : $7184-7188$

Moulder S, Yakes F, Muthuswamy S, Bianco R, Simpson J, Arteaga C (2001) Epidermal growth factor receptor (HER1) tyrosine kinase inhibitor ZD1839 (Iressa) inhibits HER2/neu (erbB2)-overexpressing breast cancer cells in vitro and in vivo. Cancer Res 61: 8887-8895

Nahta R, Esteva F (2003) HER-2-targeted therapy: lessons learned and future directions. Clin Cancer Res 9: 5078-5084

Noberasco C, DePas T, Curigliano G, Manzoni S, Dodaro L, Pelosi G, Spaggiari L, De Braud F (2005) Immunohistochemical detection of HER1/HER2 can be considered a predictive marker of gefitinib activity in non-small-cell lung cancer? J Clin Oncol 23: 921 - 922

Normanno N, Campiglio M, De Luca A Somenzi G, Maiello M, Ciardiello F, Gianni L, Salomon D, Menard S (2002) Cooperative inhibitory effect of ZD1839 (Iressa) in combination with trastuzumab (Herceptin) on human breast cancer cell growth. Ann Oncol 13: 65-72

Paez J, Janne P, Lee J, Tracy S, Greulich H, Gabriel S, Herman P, Kaye F, Lindeman N, Boggon T, Naoki K, Sasaki H, Fujii Y, Eck M, Sellers W, Johnson B, Meyerson M (2004) EGFR mutations in lung cancer: correlation with clinical response to gefitinib therapy. Science 304: $1458-1461$

Pegram M, Konecny G, O'Callaghan C, Beryt M, Pietras R, Slamon D (2004) Rational combinations of trastuzumab with chemotherapeutic drugs used in the treatment of breast cancer. J Natl Cancer Inst 96: 739-749

Perez-Soler R (2004) Phase II clinical trial data with the epidermal growth factor receptor tyrosine kinase inhibitor erlotinib (OSI-774) in nonsmall-cell lung cancer. Clin Lung Cancer 6: S20 - S23

Pollice A, McCoy J, Shackney S, Smith C, Agarwal J, Burholt D, Janocko L, Hornicek F, Singh S, Hartsock R (1992) Sequential paraformaldehyde and methanol fixation for simultaneous flow cytometric analysis of DNA, cell surface proteins, and intracellular proteins. Cytometry 13: $432-444$

Riese D, van Raaij T, Plowman G, Andrews G, Stern D (1995) The cellular response to neuregulins is governed by complex interactions of the erbB receptor family. Mol Cell Biol 15: 5770-5776

Saltz L, Meropol N, Loehrer PS, Needle M, Kopit J, Mayer R (2004) Phase II trial of cetuximab in patients with refractory colorectal cancer that expresses the epidermal growth factor receptor. J Clin Oncol 22: 1201 1208

Saltz L, Rubin M, Hochster H, Tchekmeydian N, Waksal H, Needle M, Lobuglio A (2001) Acne-like rash predicts response in patients treated with cetuximab (IMC-225) plus irinotecan (CPT-11) in CPT-11refractory colorectal cancer (CRC) that expresses epidermal growth factor receptor (EGFR). Clin Cancer Res 7: 3766S poster number 559

Sirotnak F, Zakowski M, Miller V, Scher H, Kris M (2000) Efficacy of cytotoxic agents against human tumor xenografts is markedly enhanced by coadministration of ZD1839 (Iressa), an inhibitor of EGFR tyrosine kinase. Clin Cancer Res 6: 4885-4892

Slamon D, Clark G, Wong S, Levin W, Ullrich A, McGuire W (1987) Human breast cancer: correlation of relapse and survival with amplification of the HER-2/neu oncogene. Science 235: 177-182

Slamon D, Godolphin W, Jones L, Hol tJ, Wong S, Keith D, Levin W, Stuart S, Udove J, Ullrich A, Press MF (1989) Studies of the HER-2/neu protooncogene in human breast and ovarian cancer. Science 244: 707-712

Slamon D, Leyland-Jones B, Shak S, Fuchs H, Paton V, Bajamonde A, Fleming T, Eiermann W, Wolter J, Pegram M, Baselga J, Norton L (2001) Use of chemotherapy plus a monoclonal antibody against HER2 for metastatic breast cancer that overexpresses HER2. New Engl J Med 44: $783-792$

Suo Z, Risberg B, Kalsson M, Willman K, Tierens A, Skovlund E, Nesland J (2002) EGFR family expression in breast carcinomas. c-erbB-2 and cerbB-4 receptors have different effects on survival. J Pathol 196: 17-25

Thor A, Edgerton S, Liu S, Moore DH, Kwiatkowski DH (2001) Gelsolin as a negative prognostic factor and effector of motility in erbB-2-positive 
epidermal growth factor receptor-positive breast cancers. Clin Cancer Res 7: 2415-2424

Tzahar E, Waterman H, Chen X, Levkowitz G, Karunagaran D, Lavi S, Ratzkin B, Yarden Y (1996) A hierarchical network of interreceptor interactions determines signal transduction by $\mathrm{Neu}$ differentiation factor/neuregulin and epidermal growth factor. Mol Cell Biol 16: 5276-5287

Vogel C, Cobleigh M, Tripathy D, Gutheil J, Harris L, Fehrenbacher L, Slamon D, Murphy M, Novotny W, Burchmore M, Shak S, Stewart S, Press M (2002) Efficacy and safety of trastuzumab as a single agent in first-line treatment of HER2-overexpressing metastatic breast cancer. J Clin Oncol 20: 719-726
Wakeling A, Guy S, Woodburn J, Ashton S, Curry B, Barker A, Gibson K (2002) ZD1839 (Iressa): an orally active inhibitor of epidermal growth factor signaling with potential for cancer therapy. Cancer Res 62: 5749 5754

Winston J, Ramanaryanan J, Levine E (2004) HER-2/neu evaluation in breast cancer are we there yet? Am J Clin Pathol 121: S33-S49

Yarden Y (2001) Biology of HER2 and its importance in breast cancer. Oncology 61: 1-13

Younes M (2005) Is immunohistochemistry for epidermal growth factor receptor expression a poor predictor of response to epidermal growth factor receptor-targeted therapy? J Clin Oncol 22: $923-924$ 